\title{
Intense Therapeutic Ultrasound for Chronic Lateral Epicondylitis Pain Reduction
}

\author{
Michael H Slayton ${ }^{1 *}$, John A Kearney ${ }^{2}$, Richard C Amodei ${ }^{1}$ and Keegan B Compton ${ }^{1}$ \\ ${ }^{1}$ Guided Therapy Systems, Inc. 33 S. Sycamore Mesa, Arizona, USA \\ ${ }^{2}$ The More Foundation, 18444 North 25th Avenue, Phoenix, Arizona, USA
}

"Corresponding author: Michael H Slayton, Guided Therapy Systems, Inc. 33 S. Sycamore Mesa, Arizona 85202-1150, USA, Tel: +1-480-649-4399; Fax: +1-480-649-1605; E-mail: m.slayton@guidedtherapy.com

Received date: March 23, 2018; Accepted date: April 05, 2018; Published date: April 18, 2018

Copyright: @ 2018 Slayton $\mathrm{MH}$, et al. This is an open-access article distributed under the terms of the Creative Commons Attribution License, which permits unrestricted use, distribution and reproduction in any medium, provided the original author and source are credited.

\begin{abstract}
Introduction: Intense therapeutic ultrasound (ITU) is a newly established ultrasound-based, non-invasive therapy in which sound waves are concentrated and focused on musculoskeletal tissue for the purpose of pain reduction. This technology produces selective thermal coagulative changes over a small controlled area while leaving the surrounding tissue unaffected and without impacting the integrity of the dermis.

Methods: A clinical study evaluating 29 patients (Age: $39-60$, Male: 59\%, Female $41 \%$ ) for the effectiveness, safety and patient tolerance of Intense Therapeutic Ultrasound (ITU) for treatment of chronic (average length of symptoms prior to treatment: 12.9 months), subcutaneous lateral Epicondylitis musculoskeletal tissue pain reduction was conducted. All patients enrolled in this IRB approved study had been previously diagnosed with Chronic Lateral Epicondylitis and had failed previous Standard-of-Care treatment regimen. Two ITU treatments were administered four weeks apart. Self-reported lateral elbow Universal Visual Analog pain scores and Patient-Rated Tennis Elbow Evaluation pain scores while performing normal daily tasks, were recorded pre-treatment (baseline measurement) and again at each follow-up time point - 4, 8, 12, and 26 weeks - after initial treatment. The goal for all subjects was to reduce overall pain and pain while performing everyday tasks by at least $25 \%$ on the average and more than $25 \%$ individually. While arbitrary, such criteria appear to be rigorous to reduce standard error and individual selfassessment variability.
\end{abstract}

Results: Successful reduction of overall pain scores at 12 and 26 weeks following the first treatment are $88 \%$ and $82 \%$ of patients meeting the pain reduction criteria respectively. Also, at the same follow-up time points, patients reported an average VAS Pain Score reduction of $59 \%$ (Week 12) and $57 \%$ (Week 26) from a pre-treatment average of 5.08 down to an average of 2.2 at week 26. Additionally, patients reported an average pain reduction while performing everyday tasks of $58 \%$ and $61 \%$ respectively. Patient satisfaction remained over $80 \%$ for all follow-up dates.

Conclusion: ITU is a promising non-invasive pain relief treatment for cases of chronic lateral epicondylitis.

Keywords: Intense therapeutic ultrasound; Tennis elbow; Chronic epicondylitis; Epicondylosis; Tendinopathy; Non-invasive therapy; Elbow pain reduction

\section{Introduction}

Intense therapeutic ultrasound (ITU) is a newly established ultrasound based therapy in which high frequency sound waves are focused into designated musculoskeletal tissue [1-4]. This produces selective thermal coagulative changes over a small controlled volume $\left(0.3-0.5 \mathrm{~mm}^{3}\right)$ while leaving the surrounding tissue unaffected and without impacting the integrity of the dermis. These coagulative changes are known to begin the body's tissue response cascade and promote collagen generation in the targeted anatomy resulting in pain reduction [5-7]. ITU has been used clinically to treat the subcutaneous musculoskeletal tissue below facial skin for the past decade and it has received CE Mark and FDA 510(k) clearance to market for nonsurgical brow and submental tissue lifting. Over 3 Million patients worldwide have been treated using this technology. Clinical studies have shown that $85 \%$ of patients receiving this treatment on facial skin tissue showed an improvement in facial lifting with no erythema, inflammation or scarring by creating the same coagulative changes to the connective tissue under the skin [1-4]. Histologically, it has been shown that ITU induces the production of dermal collagen with thickening of the dermis and straightening of the elastic fibers in the reticular dermis [1-4]. Previous research in laboratory studies has shown that ITU can improve healing of damaged Achilles tendons in a rabbit model. Laboratory studies have shown that ITU can improve healing of damaged Achilles tendons in both a rabbit and rat model [5-7]. Preliminary results showed an increase in precursor markers for collagen regeneration (e.g. VEGFa, TNFa, IL-1 $\beta$, and TGF $\beta 1$ ) and subsequent increase in collagen formation in injured rabbit tendons treated with ITU compared to injured, untreated rabbit tendons [5-7]. This study applied ITU to human subcutaneous musculoskeletal tissue to determine if this technology will begin the same collagen regeneration response to reduce pain within these chronic, degenerative structures. 
Acute and Chronic pain of the Common Extensor Tendon (CET) region, or lateral epicondylitis/lateral epicondylalgia, or tennis elbow is a common pathology of both athletes and non-athletes affecting 1 to $3 \%$ of the population at large [8]. While the prevalence of chronic problems caused by overuse in tennis players can be as high as $40 \%$; elbow tendinopathy represents an important set of pathologies that account for lost recreation time, decreased quality of life, and workrelated disability claims. As an example, medial and lateral epicondylitis was responsible for $11.7 \%$ of work-related injury claims in Washington State from 1987 to 1995, resulting in an average direct workers' compensation cost of $\$ 6,593$ per case [9]. Elbow tendinopathy has widespread social, financial, and clinical implications. WalkerBone et al. [10] assessed the significant effect of medial and lateral epicondylitis on workplace absences in a cross-sectional sample of 9,696 working-aged adults.

A single-blinded, pivotal study evaluating the effectiveness, safety and patient tolerance for the use of Intense Therapeutic Ultrasound (ITU) as a treatment to reduce pain in patients diagnosed with chronic lateral epicondylitis was completed at The More Foundation/CORE Institute in Phoenix, AZ. A total 29 patients received 2 treatments, 4 weeks apart on subcutaneous musculoskeletal tissues along with Standard of Care treatments as prescribed by the Principal Investigator. Patients were followed for up to 6 months after the first treatment receiving a physical exam at each follow-up visit (at 4, 8, and 12 weeks) and providing feedback via standardized Visual Analog Scale (VAS) [8] for overall pain, Patient/Subject Reported Outcome Measure (SROM) [11] and Patient-Rated Tennis Elbow Evaluation (PRTEE) surveys specific lateral epicondylitis [8]. The objective of this study is to reduce pain by at least $25 \%$ compared to the baseline during the follow-up period.

\section{Materials and Methods}

\section{Materials}

ITU treatments administered using the Actisound System - Intense Therapeutic Ultrasound by Guided Therapy Systems, Inc. (Mesa, AZ, USA). Diagnostic ultrasound images (Figure 1) were acquired on a SparkTM system manufactured by Ardent Sound, Inc. (Mesa, AZ, USA).

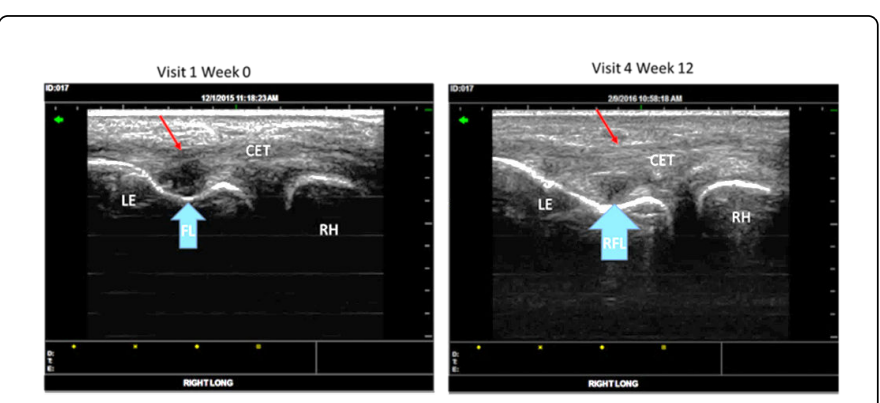

Figure 1: Diagnostic ultrasound images. LE: Lateral Epicondyle; RH: Radial Head; CET: Common Extensor Tendon (Red Arrows); FL; Fluid (Visit 1); RFL: Resolving Fluid (Visit 4).

All treatments and diagnostic ultrasound images were performed by trained personnel.

\section{Inclusion/exclusion criteria}

Subjects previously diagnosed with lateral epicondylitis and were experiencing unilateral chronic pain ( $>90$ days) after standard-of-care regimens, usually involving a multifactorial approach that may include a combination of rest (complete or modified activity), medication (NSAIDs for Epicondylitis), stretching and strength training [11], failed to relieve pain on the lateral elbow were included in the study. Patients had been experiencing symptoms for an average of 12.9 months - with a range of $3-24$ months. Only 3 patients were experiencing symptoms from $3-6$ months. In many cases, patients had previously undergone more aggressive therapy regimens, i.e., tenotomy, Platelet Rich Plasma (PRP) and/or cortisone injections - all of which had failed to reduce pain for an extended period of time. Subjects provided both written and verbal consent as well as willingness to complete treatment and post-treatment regimen as prescribed. Those included in the study did not have a history of surgery to the area of interest or participate in any alternative treatments within the last 90 days.

Patients concurrently enrolled in any other non-conservative, device, or Investigational New Drug clinical trial, or who have participated in a clinical study involving the Common Extensor Tendon (CET), thirty days prior to study initiation and patients who have received previous treatment in the symptomatic limb (not including conservative treatment) were excluded from the study. Also, at the principal investigator's discretion, subjects were excluded based on their current condition or medical history.

\section{Treatment}

Subjects underwent 2 treatments; the first at their baseline assessment, Visit 1, Week 0, and the second at Visit 3, Week 4. A series of ultrasound pulses, ranging from 80-200 in total with an energy level of 1 joule (1J) were administered to the lateral epicondyle, approximately 4-6 $\mathrm{mm}$ below the skin line, for each treatment. After treatment, patients engaged in additional standard care remedies from home, including ice packs and stretching, and logged the frequency of these.

\section{Measurements}

Pain level: Overall pain level at the CET was self-reported by subjects at pre-treatment (used as baseline measurement) and again at each follow-up - 4, 8, 12, and 26 weeks - after initial treatment. The Visual Analog Score (VAS) pain scale subjects used to identify their level of pain was a 10 -point pain scale range, where $0=$ no pain, $1=$ slight pain through 10 which equates to the patient's worst imaginable pain.

Patient rated tennis elbow evaluation score: Patients self-reported answers to questions from the Patient Rated Tennis Elbow Evaluation (PRTEE) questionnaire, which has been standardized for use in research studies to evaluate patient's level of pain and function [8]. Scores range from $0-100$, with 0 indicating no pain and 100 indicating the worst pain imaginable in a variety of daily activities involving use of the CET. Self-reported scores were taken at baseline and each follow-up time point.

SROMs, patient satisfaction and treatment pain: Self-Reported Outcome Measures (SROMs) [9,11] assessing each patients' progress were completed during each follow-up time point. The questions pertained to patients' assessments of overall personal improvement 
Citation: Slayton MH, Kearney JA, Amodei RC, Compton KB (2018) Intense Therapeutic Ultrasound for Chronic Lateral Epicondylitis Pain

Page 3 of 6

compared to baseline tracked on a 3-point scale, pain reduction compared to baseline tracked on a 4-point scale, percentage change in elbow pain, change in pain compared to baseline tracked on a 5-point scale, and percentage change in daily activities compared to baseline. Overall Patient Satisfaction was also tracked using a patient reported 4-point scale [10,11,12]: Totally Satisfied, Satisfied with Minor Reservations, Satisfied with Major Reservations, and Dissatisfied. Using the same Universal VAS pain scale, patient tolerance for the treatment was evaluated and their post-treatment experience as it relates to treatment's safety.

\section{Statistical analysis}

Both VAS pain scores and PRTEE scores reported at follow-up time points were compared to their corresponding baseline scores for each subject to determine if the goal was met by dividing the difference of the two by the baseline pain score. The percentage of subjects that met the pain reduction goal was calculated at each time point by dividing the number of subjects that achieved the pain reduction goal at each time point by the total number of patients that gave a pain score for that time point.

Student T-tests were utilized to determine statistically significant differences between baseline and subsequent follow-up measurements for self-reported measurements. All error bars displayed in graphs are standard error. The level of significance $(\alpha)$ was set to 0.05 .

\section{Results}

\section{Patient population and attrition}

Table 1 shows the statistics of the study group. 29 Patients were included in this study; 12 females and 17 males. The age range of the study group was 39-60 years old, with a median age of 46 . The number of patients declined slightly over the course of the study due to attrition, with 29 patients at week 4, 26 patients at week 8, 25 patients at week 12 , and 22 patients at week 26 .

\begin{tabular}{|c|c|c|c|c|c|}
\hline $\begin{array}{c}\text { The More Foundation, } \\
\text { Common Extensor Tendon }\end{array}$ & Baseline & $\begin{array}{c}\text { Week } \\
\mathbf{4}\end{array}$ & $\begin{array}{c}\text { Week } \\
\mathbf{8}\end{array}$ & $\begin{array}{c}\text { Week } \\
\mathbf{1 2}\end{array}$ & $\begin{array}{c}\text { Week } \\
\mathbf{2 6}\end{array}$ \\
\hline Number of Patients & 29 & 29 & 26 & 25 & 22 \\
\hline Age, Years, Baseline (range) & \multicolumn{3}{|c|}{$46(39-60)$} \\
\hline $\begin{array}{c}\text { Average No. of Months, } \\
\text { Symptomatic, (Range) }\end{array}$ & $\begin{array}{c}12.9 \text { Months (3-24) with 3 patients, less than } \\
6 \text { months }\end{array}$ \\
\hline Gender, M/F, (\%) & \multicolumn{3}{|c|}{17 (58.6\%) / 12 (41.4\%) } \\
\hline
\end{tabular}

Table 1: Patient population and statistics.

\section{Pain score reduction}

Table 2 shows the number of patients at each of the baseline selfreported VAS pain scores. At each follow-up time point, the number of responding patients and the number of patients meeting the individual criteria of higher than $25 \%$ pain reduction from the baseline are shown. A majority of patients met or exceeded the criteria of $25 \%$ pain reduction according to the self-reported VAS pain score, up to $88 \%$ at week 12 .

\begin{tabular}{|c|c|c|c|c|c|c|c|c|c|}
\hline $\begin{array}{l}\text { Baseline Pain } \\
\text { Score }\end{array}$ & $\begin{array}{l}\text { Baseline } \mathrm{N} \text { at } \\
\text { each pain } \\
\text { score }\end{array}$ & $\begin{array}{c}\text { No. of } \\
\text { Patients } \\
\text { assessed at } 4 \\
\text { weeks }\end{array}$ & $\begin{array}{c}\text { No. of } \\
\text { Patients } \\
\text { meeting } \\
\text { primary pain } \\
\text { criteria at } 4 \\
\text { weeks }\end{array}$ & $\begin{array}{c}\text { No. of } \\
\text { Patients } \\
\text { assessed at } 8 \\
\text { weeks }\end{array}$ & $\begin{array}{c}\text { No. of } \\
\text { Patients } \\
\text { meeting } \\
\text { primary pain } \\
\text { criteria at } 8 \\
\text { weeks }\end{array}$ & $\begin{array}{l}\text { No. of } \\
\text { Patients } \\
\text { assessed at } \\
12 \text { weeks }\end{array}$ & $\begin{array}{c}\text { No. of } \\
\text { Patients } \\
\text { meeting } \\
\text { primary pain } \\
\text { criteria at } 12 \\
\text { weeks }\end{array}$ & $\begin{array}{c}\text { No. of } \\
\text { Patients } \\
\text { assessed at } \\
26 \text { weeks }\end{array}$ & $\begin{array}{c}\text { No. of } \\
\text { Patients } \\
\text { meeting } \\
\text { primary pain } \\
\text { criteria at } 26 \\
\text { weeks }\end{array}$ \\
\hline 10 & 0 & 0 & 0 & 0 & 0 & 0 & 0 & 0 & 0 \\
\hline 9 & 0 & 0 & 0 & 0 & 0 & 0 & 0 & 0 & 0 \\
\hline 8 & 5 & 5 & 4 & 4 & 4 & 4 & 4 & 4 & 4 \\
\hline 7 & 2 & 2 & 2 & 2 & 2 & 1 & 1 & 2 & 2 \\
\hline 6 & 6 & 6 & 6 & 6 & 4 & 6 & 6 & 6 & 5 \\
\hline 5 & 2 & 2 & 2 & 2 & 1 & 2 & 2 & 1 & 1 \\
\hline 4 & 7 & 7 & 5 & 5 & 4 & 5 & 4 & 4 & 3 \\
\hline 3 & 4 & 4 & 2 & 4 & 3 & 4 & 3 & 3 & 2 \\
\hline 2 & 3 & 3 & 3 & 3 & 2 & 3 & 2 & 2 & 1 \\
\hline 1 & 0 & 0 & 0 & 0 & 0 & 0 & 0 & 0 & 0 \\
\hline Total & 29 & 29 & 24 & 26 & 20 & 25 & 22 & 22 & 18 \\
\hline $\begin{array}{c}\% \text { Meeting } \\
\text { Criteria }\end{array}$ & & 0.68 & & & 0.77 & & 0.88 & & 0.82 \\
\hline
\end{tabular}

Table 2: Patient reported pain scores by visit and \% meeting pain reduction criteria. 
Citation: Slayton MH, Kearney JA, Amodei RC, Compton KB (2018) Intense Therapeutic Ultrasound for Chronic Lateral Epicondylitis Pain

Figure 2 shows a highly significant drop in average reported pain score (VAS) for all time points compared to baseline $(\mathrm{p}<0.001)$, dropping below half the original baseline average by week 12 . The blue bars represent the average reported pain score at baseline and at each follow-up timepoint. The Gold Bars show the average percent pain score reduction at each follow-up time point, compared to baseline.

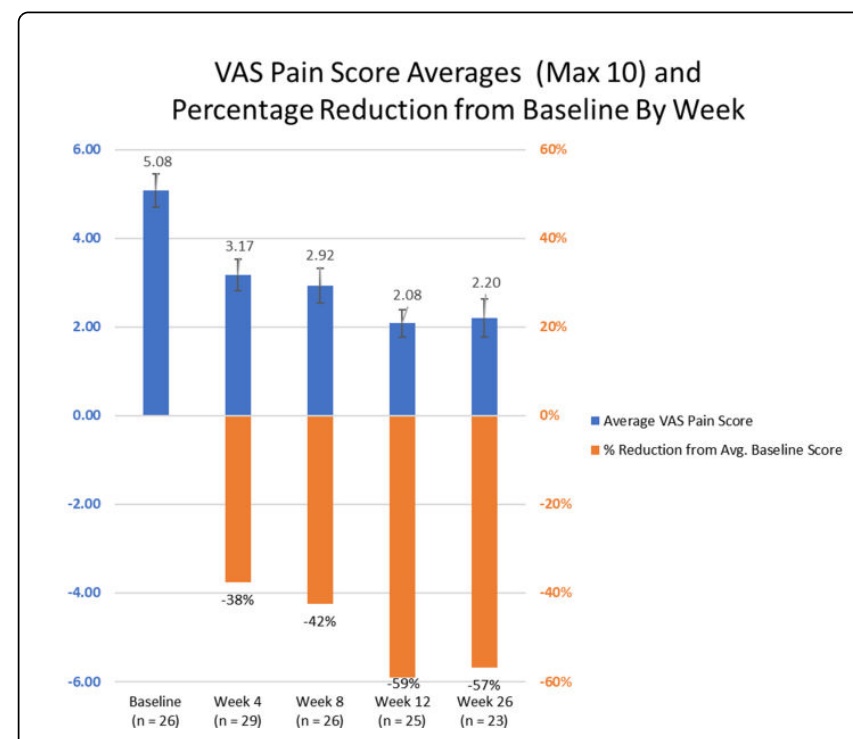

Figure 2: Average pain score and \& pain reduction by visit $(\mathrm{p} \leq$ 0.001) standard error noted.

\section{PRTEE score reduction}

In Figure 3, the blue bars show the average reported pain score based on normal daily activities at baseline and at each follow-up timepoint. There is significant reduction when compared to baseline ( $\mathrm{p}<0.001$ for all follow-up dates). The gold bars demonstrate a $\%$ reduction from baseline is cut by approximately $60 \%$ by week 12 and continuing to week 26 .

\section{SROMs}

Table 3 shows the results of SROMs answered by patients at each timepoint. At every timepoint following the second treatment (Week 4), a majority of patients felt better and experienced at least a $25 \%$ improvement in pain and daily activities. The proportion of patients that felt improvement in these categories increased at each subsequent timepoint. The table shows the percentage of patients that met each criterion in the Self-Reported survey.

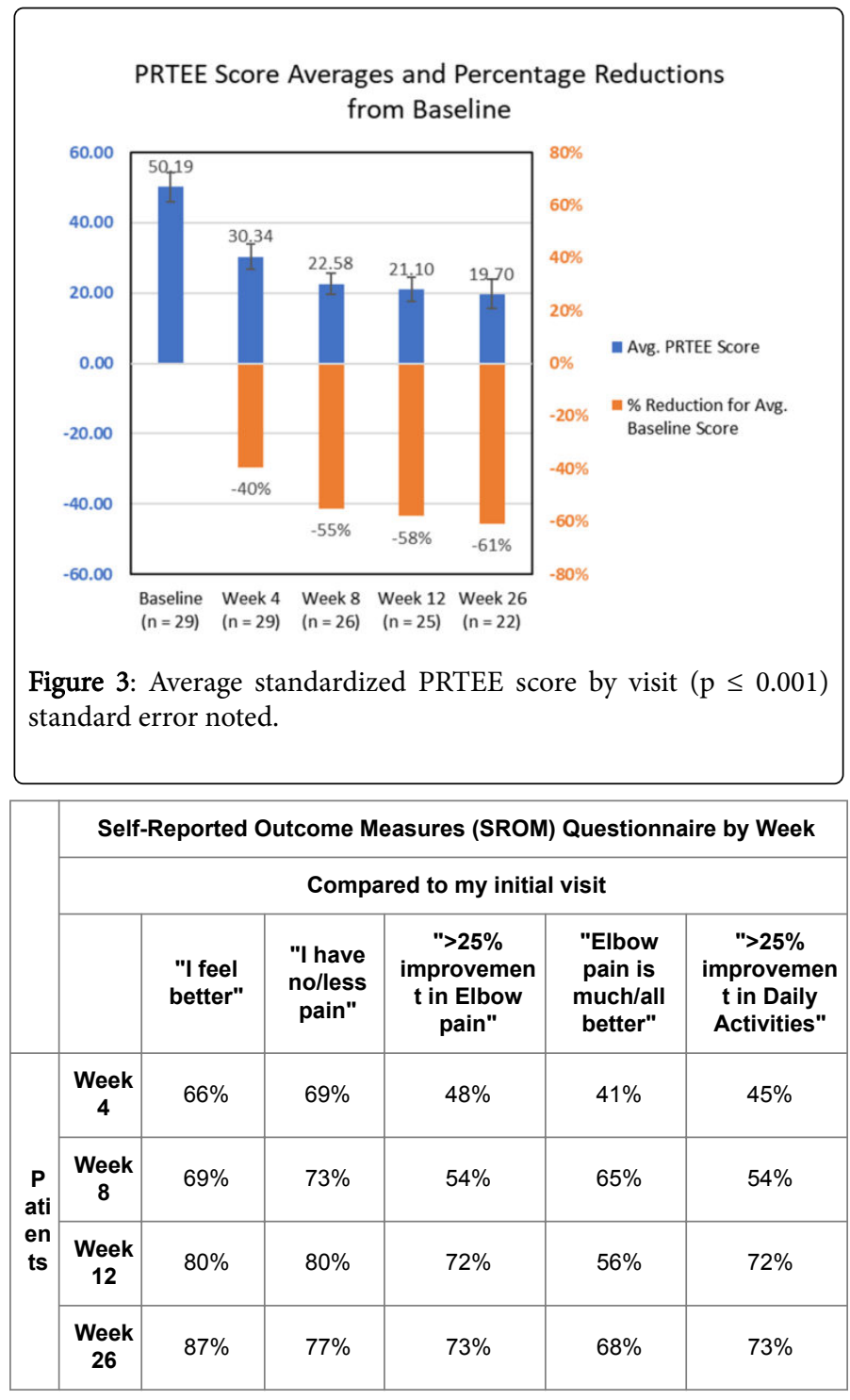

Table 3: Patient self-reported outcome measure (RROMSs) by week.

\section{Patient satisfaction}

Self-Reported Overall Patient Satisfaction was tracked on a 4-point scale. Patients meeting the satisfaction criteria either reported that they were totally satisfied or satisfied with minor reservations. At each follow-up time point patient satisfaction, based on these criteria was between $76 \%$ and $97 \%$ (Gold Bars). Additionally, we tracked those patients reporting satisfaction, with major reservations (White Bars). Figure 4 shows patient satisfaction was recorded between $80 \%$ and $100 \%$. 


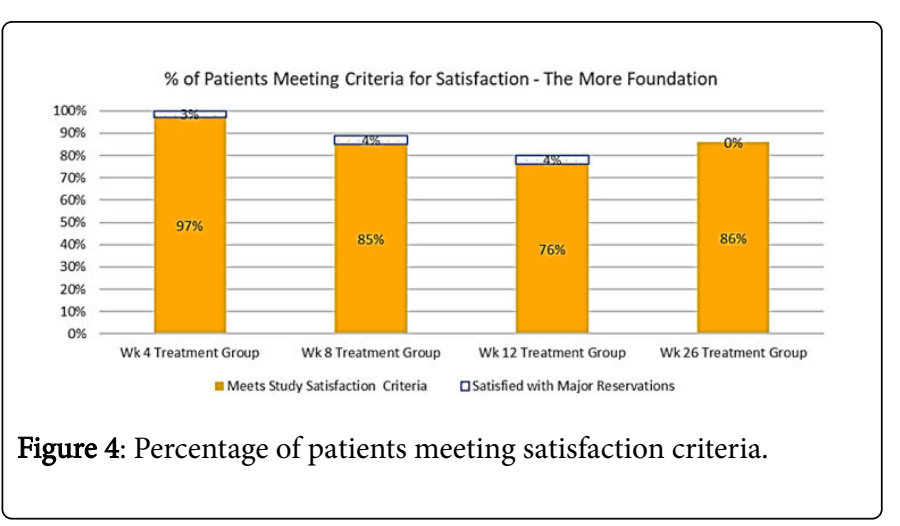

\section{Treatment pain}

No anesthetic or analgesic was used during the ITU treatments. For treatment 1 , the average pain score was $4.9 ; 84 \%$ of patients reported average pain scores of 4.3 and a range of $0-8$, while $16 \%$ had momentary and infrequent pain score spikes up to 10 . No patients interrupted treatment due to intolerable pain during the first round of treatments. For treatment 2, the average pain score was $4.7 ; 83 \%$ of patients reported average pain scores of 4.1 and a range of $0-8$, while $17 \%$ had momentary and infrequent pain score spikes up to 10 . No patients interrupted treatment due to intolerable pain during the rounds of treatments and no attrition was associated with treatment pain.

\section{Discussion}

The results of this study correlate well with the findings of the facial musculoskeletal studies [1-4] and other musculoskeletal studies currently utilizing ITU.

Based on the results of our study, intense therapeutic ultrasound (ITU) has potential to become a widely used treatment for chronic tennis elbow. Having statistically significant reduction on both pain and functional limitations within the first 4 weeks and maintaining that reduction through 26 weeks; demonstrates solid evidence that ITU can be effective for treating tennis elbow and possibly other musculoskeletal conditions. In fact, we've achieved similar results in other study centers focusing on the treatment of plantar fasciitis using the same ITU technology [13]. Using ITU for the treatment of various tendinopathies, like the two conditions listed above, is favorable due to superficial nature of the injury. With the scale of target depth being millimeters, this allows energy-based technologies to remain a noninvasive treatment options for those patients whom conventional treatment options remain ineffective and do not wish to have surgery.

Extracorporeal shockwave treatment (ESWT) is a very different ultrasound-based technology that has been used as a non-invasive musculoskeletal treatment. In literature, ESWT has achieved mixed results with the treatment of tennis elbow and is reported to be extremely painful during and after treatment. A study performed by Crowther MAA et al. comparing ESWT and steroid injection showed a significant difference in pain reduction favoring steroid injection after 3 months; in addition, the same study provided an estimation of treatment cost to patients to be 100-fold for the ESWT method over injection [12]. Another study by Haake $M$ et al. studying the sideeffects of ESWT treatment for tennis elbow said that treatment pain was the second-most frequent side-effect after skin reddening and significantly more frequently than the placebo group [14]. ESWT treatment regimens vary in several studies, between 2000-3000 pulses most commonly [11,13-15]. With treatment frequency around 120-240 pulses per minute, this means treatments last around 10-30 minutes. In comparison, ITU treatments for our study lasted less than 2 minutes, while achieving significant improvement in pain reduction and return to normal activity.

Injections are a commonly used method of treatment for tennis elbow, yet long term success is varied with this choice depending on the type of injection. The Crowther MAA et al. study found more success using steroid injections over ESWT, though this study extended only to 3 -months from treatment [12]. Platelet-rich plasma injections have had mixed success, one study showing significantly differing success from control only at 24 weeks [16] while another study had a significant difference from an autologous blood injection only in the short-term of 6 weeks [9] Injections of sodium hyaluronate have been explored as a possible treatment due to the highly preserved structure and biocompatibility of hyaluronan (HA) and its role in the lubrication of tissues in the body. Results of a study by Petrella et al. show significant difference between HA-treated individuals and the control group in both pain reduction and grip strength at 12 months beyond treatment [17].

Tenotomy is another method of treatment that is considered minimally invasive requiring the patient to be locally anesthetized. Though success rates are high in the long-term, recovery can be a length process; for example, a study performed by Koh et al. showed that tendon thickness and echogenicity took 6 months to return to normal levels following their tenotomy procedure [18]. The same findings with hypoechoic scar tissue resolving itself after 6 months in $90 \%$ of patients were found in a study performed by Seng et al. [19]. Despite the longer recovery period, tenotomy has had high levels of success across many studies in both pain reduction and patient satisfaction [20-23].

\section{Conclusion}

This study has shown the effectiveness, safety and patient tolerability of ITU therapy for pain relief and improved function for patients suffering from chronic lateral epicondylitis. Patients reported an average of $57 \%$ reduction in Pain Scores (VAS) and an $80 \%$ overall treatment satisfaction at 26 weeks. Considering all patients were diagnosed with chronic tennis elbow, and previous standard of care treatment options had failed to reduce pain or improve daily function, ITU for chronic musculoskeletal pain could be considered as an important tool for the treatment of chronic tennis elbow. Furthermore, patient-reported satisfaction and return-of-function for the affected area further provide evidence for the potential ITU has for becoming a non-invasive, patient-friendly treatment that requires no down time allowing patients to return to their normal activities within weeks.

\section{Funding}

Guided Therapy Systems funded this study. No additional financial support was received by the authors for the work completed in this submission.

\section{References}

1. White MW, Makin IR, Barthe PB, Slayton MH, Gliklich RE (2007) Selective Creation of Thermal Injury Zones in the Superficial Musculoaponeurotic System Using Intense Ultrasound Therapy A New 
Citation: Slayton MH, Kearney JA, Amodei RC, Compton KB (2018) Intense Therapeutic Ultrasound for Chronic Lateral Epicondylitis Pain Reduction. J Sports Med Doping Stud 8: 202. doi:10.4172/2161-0673.1000202

Page 6 of 6

Target for Noninvasive Facial Rejuvenation. Arch Facial Plastic Surgery 9 22-29.

2. Alam M, White LE, Martin N, Witherspoon J, Yoo S, et al. (2010) Ultrasound Tightening of Facial and Neck Skin: A Rater-Blinded Prospective Cohort Study. J Am Acad Dermatol 62: 262-269.

3. Gliklich RE, White WM, Slayton MH, Barthe PG, Makin IR (2007) Clinical Pilot Study of Intense Ultrasound Therapy to Deep Dermal Facial Skin and Subcutaneous Tissues. Arch Facial Plast Surg 9: 88-95.

4. Laubach HA, Makin IR, Barthe PG, Slayton MH, Manstein D (2008) Intense Focused Ultrasound: Evaluation of a New Treatment Modality for Precise Microcoagulation within the Skin. Dermatol Surg 34: 727-734.

5. Slayton MH, Barton JK (2014) Feasibility of Modulating Healing Tissue Response by ITU (Intense Therapy Ultrasound) in Musculoskeletal Tissue. American Society for Laser Medicine and Surgery Abstracts.

6. Barton JK, Rice PF, Howard CC, Koevary JW, Danford FL, et al. (2018) Structural and Functional Assessment of Intense Therapeutic Ultrasound Effects on Partial Achilles Tendon Transection. Proceedings in Advanced Biomedical and Clinical Diagnostic and Surgical Guidance Systems.

7. Molloy T, Wang Y, Murrell GAC (2003) The Roles of Growth Factors in Tendon and Ligament Healing. Sports Med 33: 381-394.

8. Rompe JD, Overend TJ, MacDermid JC (2007) Validation of the Patientrated Tennis Elbow Evaluation Questionnaire. J Hand Ther 20: 3-10.

9. Thanasas C, Papadimitriou G, Charalambidis C, Paraskevopoulos I, Papanikolaou A (2011) Platelet-Rich Plasma Versus Autologous Whole Blood for the Treatment of Chronic Lateral Elbow Epicondylitis: A Randomized Controlled Clinical Trial. Am J Sports Med 39: 2130-2134.

10. Walker-Bone K, Palmer KT, Reading I, Coggon D, Cooper C (2004) Prevalence and Impact of Musculoskeletal Disorders of the Upper Limb in the General Population. Arthritis Rheum 51: 642-651.

11. DiGiovanni BF, Nawoczenski DA, Lintal ME, Moore EA, Murray JC, et al (2003) Tissue-Specific Plantar Fascia-Stretching Exercise Enhances Outcomes in Patients with Chronic Heel Pain. A Prospective, Randomized Study. J Bone Joint Surg Am 85: 1270-1277.

12. Crowther MA, Bannister GC, Huma H, Rooker GD (2002) A prospective, Randomized Study to compare Extracorporeal Shock-Wave Therapy and Injection of Steroid for the Treatment of Tennis Elbow. J Bone Joint Ther 84: 678-679.

13. Slayton MH, Amodei RC, Compton KB, Latt D, Kearny J (2016) Musculoskeletal Treatments using Intense Therapy Ultrasound: Clinical
Studies for Chronic Plantar Fasciitis and Lateral Epicondylitis. IEEE Healthcare Innovation Point-Of-Care Technologies Conference (HIPOCT).

14. Haake M, Böddeker IR, Decker T, Buch M, Vogel M, et al. (2002) Sideeffects of Extracorporeal Shock Wave Therapy (ESWT) in the Treatment of tennis elbow. Arch Orthop Trauma Surg 122: 222-228.

15. Gündüz R, Malas FÜ, Borman P, Kocaoğlu S, Özçakar L (2012) Physical Therapy, Corticosteroid Injection, and Extracorporeal Shock Wave Treatment in Lateral Epicondylitis: Clinical and Ultrasonographical Comparison. Clin Rheumatol 31: 807-812.

16. Mishra AK, Skrepnik NV, Edwards SG, Jones GL, Sampson S, et al. (2013) Efficacy of Platelet-Rich Plasma for Chronic Tennis Elbow: A DoubleBlind, Prospective, Multicenter, Randomized Controlled Trial of 230 Patients. Am J Sports Med 42: 463-471.

17. Petrella RJ, Cogliano A, Decaria J, Mohamed N, Lee R (2010) Management of Tennis Elbow with Sodium Hyaluronate Periarticular Injections. Sports Med Arthrosc Rehabil Ther Technol 2: 4.

18. Koh JS, Mohan PC, Howe TS, Lee BP, Chia SL, et al. (2013) Fasciotomy and Surgical Tenotomy for Recalcitrant Lateral Elbow Tendinopathy: Early Clinical Experience With a Novel Device for Minimally Invasive Percutaneous Microresection. Am J Sports Med 41: 636-644.

19. Seng C, Mohan PC, Koh SB, Howe TS, Lim YG, et al. (2015) Ultrasonic Percutaneous Tenotomy for Recalcitrant Lateral Elbow Tendinopathy: Sustainability and Sonographic Progression at 3 Years. Am J Sports Med 44: 504-510.

20. Barnes DE, Beckley JM, Smith J (2015) Percutaneous Ultrasonic Tenotomy for Chronic Elbow Tendinosis: A Prospective Study. J Shoulder Elbow Surg 24: 67-73.

21. Tasto JP, Richmond JM, Cummings JR, Hardesty R, Amiel D (2016) Radiofrequency Microtenotomy for Elbow Epicondylitis: Midterm Results. Am J Orthop (Belle Mead NJ) 45: 29-33.

22. Tasto JP, Cummings J, Medlock V, Hardesty R, Amiel D (2005) Microtenotomy Using a Radiofrequency Probe to Treat Lateral Epicondylitis. Arthroscopy 21: 851-860.

23. Solheim E, Hegna J, Øyen J (2013) Arthroscopic Versus Open Tennis Elbow Release: 3- to 6-Year Results of a Case-Control Series of 305 Elbows. Arthroscopy 29: 854-859. 